\title{
Photoinitiated Intramolecular Proton Transfer in Deprotonated para-Coumaric Acid
}

\author{
James N. Bull, ${ }^{*, \dagger}$, Gabriel da Silva, ${ }^{\top}$ Michael S. Scholz, ${ }^{\dagger}$ Eduardo Carrascosa, ${ }^{\dagger}$ \\ and Evan J. Bieske*,† \\ $\dagger$ School of Chemistry, University of Melbourne, Parkville, VIC 3010, Australia \\ $\ddagger$ School of Chemistry, Norwich Research Park, University of East Anglia, Norwich NR4 \\ 7TJ, United Kingdom \\ IDepartment of Chemical Engineering, University of Melbourne, Parkville, VIC 3010, \\ Australia
}

E-mail: james.bull@eigenket.org; evanjb@unimelb.edu.au 


\begin{abstract}
Deprotonated para-coumaric acid is commonly considered as a model for the chromophore in photoactive yellow protein which undergoes $E \rightarrow Z$ isomerization following absorption of blue light. Here, tandem ion mobility mass spectrometry is coupled with laser excitation to study the photochemistry of deprotonated para-coumaric acid, to show that the $E$ isomers of the phenoxide and carboxylate forms have distinct photochemical responses with maxima in their action spectra at 430 and $360 \mathrm{~nm}$, respectively. The $E$ isomer of the phenoxide anion undergoes efficient autodetachment upon excitation of its lowest $\pi \pi^{*}$ transition. For the $E$ isomer of the carboxylate deprotomer, a one-way photoinitiated proton transfer generates the phenoxide deprotomer through a mechanism postulated to involve an excited-state enol-keto tautomerism followed by a series of ground state rearrangements including a second proton transfer. This mechanism is supported by experiments in which the relevant intermediate keto isomer is prepared and spectroscopically probed, and through master equation modelling of possible ground state isomerization processes. The $Z$ isomer of the carboxylate deprotomer shows a weak $Z \rightarrow E$ photoisomerization response that occurs in competition with photodestruction (presumably electron detachment), demonstrating that the $E$ and $Z$ isomers undergo different processes in their excited states. The study highlights the utility of isomer-selective spectroscopy for characterizing the photochemistry of isolated anions possessing multiple deprotonation sites.
\end{abstract}

\title{
Introduction
}

Photoactive yellow protein (PYP) is a small photoreceptor that functions as a blue light sensor in certain bacteria. ${ }^{1,2}$ In PYP, absorption of blue light induces rapid $E \rightarrow Z$ isomerization of the chromophore, ${ }^{3}$ initiating a cascade of conformational changes of the host protein that eventually causes negative phototaxism of the bacterium. ${ }^{4}$ The protein is recycled after several seconds through thermal isomerization. The details of the PYP photocycle have been studied using a range of ultrafast vibrational spectroscopic techniques 
- see, for example, references 5 and 6 - and recently confirmed using time-resolved Laue crystallography and time-resolved serial crystallography whereby the atomic motions of the chromophore and protein were monitored in real time. ${ }^{7-10}$ Other time-resolved spectroscopy and neutron diffraction studies suggest the photocycle may involve a proton transfer from the chromophore's hydroxyl group to a hydrogen-bonded amino acid residue, ${ }^{11-13}$ a transformation that is difficult to observe with X-ray diffraction. The chromophore in PYP is a deprotonated (anionic) phenolic-thioester molecule, which is structurally similar to the paracinnamate anions shown in Figure 1. Cinnamate-based chromophores are also widespread in the Plantae kingdom, functioning as photoprotecting sunscreens in the epidermal cell layers of leaves. ${ }^{14,15}$ Their efficacy in this context relies on high absorption cross-sections for UV light and efficient conversion of electronic energy into vibrational motion via passage through a conical intersection located along an $E-Z$ isomerization coordinate. ${ }^{16,17}$ This efficient internal conversion also underlies the operation of cinnamate-based molecules as UV-B filters in cosmetic sunscreens. ${ }^{18}$
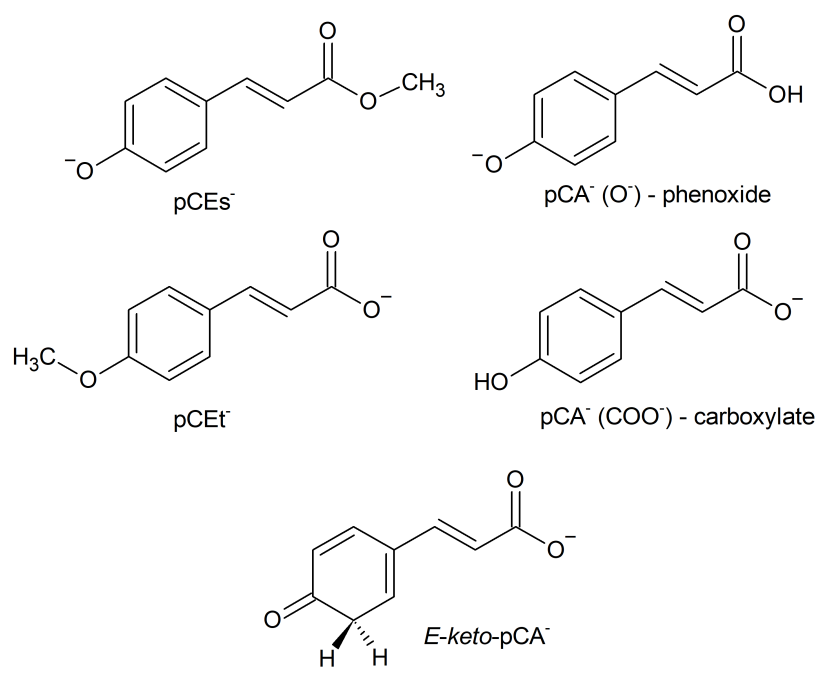

Figure 1: $E$ isomers of the para-cinnamate anions considered in this study. Key: $\mathrm{pCA}^{-}$ $\left(\mathrm{O}^{-}\right)$- phenoxide deprotonated para-coumaric acid, $\mathrm{pCA}^{-}\left(\mathrm{COO}^{-}\right)$- carboxylate deprotonated para-coumaric acid, $\mathrm{pCEs}^{-}$- deprotonated para-coumaric methyl ester, $\mathrm{pCEt}^{-}{ }^{-}$ deprotonated para-coumaric methyl ether, and E-keto-pCA ${ }^{-}$- deprotonated keto tautomer of $E$-pCA ${ }^{-}\left(\mathrm{COO}^{-}\right)$which was photogenerated in the gas phase.

Over the last two decades there have been numerous studies of cinnamate-based chro- 
mophores targeted at characterizing their photoisomerization mechanism and efficiency. Solution-based studies suggest that the intrinsic photoisomerization efficiency and timescale are modified by the deprotonation state, deprotonation site, solvent interactions, functional group substitution, and torsion-locking the single bond linking the carboxylic acid tail to the phenyl ring. ${ }^{19-25}$ Theoretical investigations indicate that solvation and substitution on the carboxylate group significantly influence the topology of the $\mathrm{S}_{1}$ potential energy surface, including the presence and energies of local minima and the conical intersection seams associated with direct internal conversion (torsion of the single bond linking the phenyl ring to the carboxylic acid tail) and $E-Z$ isomerization of the alkene bond. ${ }^{26-32}$ Changes that promote relaxation of the excited state population via direct internal conversion reduce the $E \rightarrow Z$ isomerization yield.

A desire to understand the inherent photochemistry and photoisomerization behaviour of cinnamate-based molecules has prompted several gas-phase studies particularly on the simplest cinnamate anion, deprotonated para-coumaric acid $\left(\mathrm{pCA}^{-}\right.$, Figure 1$)$. This molecule has acidic phenol and carboxylic acid groups, which, when deprotonated, give phenoxide and carboxylate deprotomers. The relative abundances of different deprotomers formed through electrospray ionization can depend on solvent, electrospray voltage and geometry, carrier/drying gas, and post-electrospray treatment of the ions. ${ }^{33,34}$ Previous spectroscopic investigations of electrosprayed $\mathrm{pCA}^{-}$have involved monitoring formation of neutral molecules (generated through photodetachment or photofragmentation over an acquisition window of several microseconds) as a function of wavelength in an ion storage ring. ${ }^{35-38}$ Photoelectron spectra have been recorded at selected wavelengths. ${ }^{39-42}$ Action spectra of phenylated or methylated derivatives such as $\mathrm{pCEs}^{-}$and $\mathrm{pCEt}^{-}$(Figure 1), for which the deprotonation site is unambiguous, have also been obtained with the ion storage ring technique. $^{35,36}$

In the current investigation, phenoxide and carboxylate deprotomers of $\mathrm{pCA}^{-}$and the methylated analogues $\mathrm{pCEs}^{-}$and $\mathrm{pCEt}^{-}$have been isolated and probed using tunable laser 
radiation in a tandem ion mobility mass spectrometer. In ion mobility spectrometry (IMS), charged isomers (e.g. $E$ and $Z$ geometric isomers and deprotomers) drifting under the influence of an electric field through a buffer gas are separated according to their drift speeds, which depend on their collision cross-sections. Typically, the target isomer is selected in a primary IMS stage and then exposed to wavelength tunable light, with separation of photoisomers or photofragments in a second IMS stage. This isomer selectivity avoids complications associated with overlapping spectra of coexisting isomers that potentially bedevil other action spectroscopies.

The present study was intended to address several issues. (1) Can the phenoxide and carboxylate deprotomers of $\mathrm{pCA}^{-}$be distinguished using ion mobility spectrometry? (2) Do the deprotomers photoisomerize or photodetach an electron in the gas phase? (3) Do the phenoxide and carboxylate deprotomers of $\mathrm{pCA}^{-}$have distinct action spectra?

\section{Experimental Methods}

The tandem ion mobility mass spectrometer used in this study has been described elsewhere. ${ }^{43,44}$ The instrument has an IMS-IMS-QMF configuration, consisting of two drift regions (IMS1 and IMS2) followed by a quadrupole mass filter (QMF). Gas-phase anions were produced by electrospraying $\mathrm{a} \approx 20 \mu \mathrm{mol} \mathrm{L}{ }^{-1}$ solution (shielded from room light) of the reagent in methanol with a drop of ammonia (electrospray voltage $-3 \mathrm{kV}$ ). The $E$ isomers of para-coumaric acid (>98\%) and the methyl ester and ether were purchased from SigmaAldrich (Castle Hill, Australia and Dorset, UK). Electrosprayed anions were transferred via a heated capillary into an RF ion funnel, which radially gathered and confined the ions. A pulsed ion gate at the end of the ion funnel injected $\approx 100 \mu$ s packets of ions at $40 \mathrm{~Hz}$ into the first drift region (IMS1) where they were propelled by an electric field $\left(44 \mathrm{~V} \mathrm{~cm}^{-1}\right)$ through $\mathrm{N}_{2}$ buffer gas at a pressure of $\approx 6$ Torr. The constituent deprotomers and geometric isomers were separated according to their different collision cross-sections with $\mathrm{N}_{2}$. After 
traversing the two drift regions (IMS1 + IMS2) a second ion funnel collected the ions and introduced them into a differentially pumped octupole ion guide and QMF where they were mass-selected before they reached a Channeltron ion detector. The detector was connected to a multichannel scaler that produced a histogram of ion counts against arrival time, $t$, corresponding to an arrival time distribution (ATD). In all presented ATDs, $t=0$ corresponds to the opening of the source ion gate.

For the photochemistry experiments, a Bradbury-Nielsen ion gate situated at the end of IMS1 was opened for $\approx 100 \mu$ s to transmit the target isomer anions. These mobility-selected isomers were exposed to a light pulse from a tunable optical parametric oscillator (OPO, EKSPLA NT342B), which induced photoisomerization or photodetachment. The OPO was operated at $20 \mathrm{~Hz}$, half the rate of ion injection, allowing accumulation of light-on and lightoff ATDs. The light fluence was limited to $<0.5 \mathrm{~mJ} \mathrm{~cm}{ }^{-2}$ pulse $^{-1}$ to minimize multiphoton processes (see SI). Following irradiation, the parent and photoproduct ions were separated according to their collision cross-sections in the second stage of the drift region (IMS2). Photodetachment from a mobility-selected isomer was detected by seeding the $\mathrm{N}_{2}$ buffer gas with trace $\mathrm{SF}_{6}$, which efficiently scavenges the electrons, and monitoring the $\mathrm{SF}_{6}{ }^{-}$yield by setting the QMF to transmit all masses. Action spectra were generated by plotting the photoproduct yield against wavelength. The signal was normalized by light fluence and light-off signal.

It is important to remember that ions are photoactivated in $\approx 6$ Torr $\mathrm{N}_{2}$ gas, such that slower processes may be suppressed due to collisional quenching. The expected collision rate is $\approx 10^{9} \mathrm{~s}^{-1}$ at 6 Torr, although hundreds of collisions are required to quench the energy imparted through absorption of a visible photon. Under these conditions, rapid excited state processes that occur on sub-nanosecond timescales, such as photoisomerization by passage through a conical intersection or autodetachment, will tend to take place. On the other hand, slower ground state processes that occur following internal conversion, including statistical dissociation or thermionic emission (electron ejection), may be suppressed because of 
collisional deactivation. ${ }^{45,46}$ The suppression of slower processes, particularly at lower photon energies, potentially may affect the shape of an action spectrum recorded by monitoring photofragments or thermionically ejected electrons. In such instances the action spectrum might not mirror the absorption spectrum.

\section{Theoretical Methods}

Electronic structure calculations were performed using the Gaussian 16, PSI4 1.1, QChem 4.4 and CFOUR 2.0b software packages. ${ }^{47-50}$ Geometrical optimizations, vibrational frequencies and transition state searches were performed at the $\omega$ B97X-D/aug-cc-pVTZ level of theory (aug-cc-pVDZ basis set for rotomer transition state searches), followed by single-point energy calculations at the FNO-CCSD $(\mathrm{T}) / \mathrm{GEN}$ or $\operatorname{CCSD}(\mathrm{T}) / \mathrm{GEN}$ level of theory. ${ }^{51-54}$ The GEN basis set is the aug-cc-pVTZ basis set with all $f$ polarization functions excluded for computational efficiency. Transition state geometries were confirmed using intrinsic reaction coordinate (IRC) analysis.

Vertical excitation energies (VEEs) for selected $\pi \pi^{*}$ states were computed with the EOMCCSD and EOM-CC3 methods while vertical detachment energies (VDEs) were computed with the EOM-IP-CCSD method. ${ }^{55-58}$ Following the study of Zuev et al. ${ }^{59}$ these calculations used RI-MP2/aug-cc-pVDZ (rimp2-cc-pVDZ auxiliary basis set) optimized geometries and either the $6-31+\mathrm{G}(\mathrm{d}, \mathrm{p})$ or aug-cc-pVDZ basis set. ${ }^{60,61}$ EOM-CC3/aug-cc-pVDZ calculations excluded virtual orbitals with energies $>2$ Hartree from the correlation space for computational tractability. The performance of each level of theory is discussed in the Supporting Information. Ground and first excited state potential energy surfaces for enol-keto tautomerism of $E$-pCA ${ }^{-}\left(\mathrm{COO}^{-}\right)$were calculated at the time-dependent $\omega \mathrm{B} 97 \mathrm{X}-\mathrm{D} / \mathrm{aug}-\mathrm{cc}-$ pVTZ level of theory.

Collision cross-sections were calculated using MOBCAL with the trajectory method parametrized for $\mathrm{N}_{2}$ buffer gas. ${ }^{62,63}$ Input charge distributions were computed at the $\omega \mathrm{B} 97 \mathrm{X}$ - 
D/aug-cc-pVTZ level of theory with the Merz-Singh-Kollman scheme constrained to reproduce the electric dipole moment. ${ }^{64}$ Sufficient trajectories were computed to give standard deviations of $\pm 1 \AA^{2}$ for the calculated values.

RRKM theory calculations using the MultiWell suite of programs were carried out to determine microscopic rate coefficients for statistical isomerization processes occurring after photoexcitation, $k_{A \rightarrow B}(E)$, where $A$ is the parent isomer, $B$ is the product isomer and $E$ is the total internal energy. ${ }^{65-67}$ In these calculations, sums and densities of states for minima and transition states were calculated from Stein-Rabinovitch-Beyer-Swinehart counts using the $\omega \mathrm{B} 97 \mathrm{X}-\mathrm{D} /$ aug-cc-pVTZ structures, vibrational frequencies, moments of inertia and zeropoint energies, while electronic energies used FNO-CCSD (T)/GEN values. The rigid rotor and symmetric top assumptions were invoked for external degrees of freedom, while the internal degrees of freedom were described as harmonic oscillators.

Energy-grained master equation simulations were performed using a modified version of MultiWell to characterize the coupled isomerization and vibrational relaxation from specific starting isomers (e.g. $Z$-pCEs ${ }^{-}, Z$-pCEt ${ }^{-}$, etc.). These simulations were designed to describe the evolution of isomer populations following formation of a vibrationally excited population on the ground electronic state manifold using rates from RRKM theory, ion-molecule collision rates from a Langevin model, and energy transfer to buffer gas molecules with a single exponential down model using the energy transfer per collision parameter $\Delta E_{d}=35 \mathrm{~cm}^{-1}$. Further details on $\Delta E_{d}$ are given in the Supporting Information. The master equation was solved for $10^{6}$ independent trajectories over $10 \mathrm{~cm}^{-1}$ energy grains, discretized into 5,000 bins. At higher energies a continuum approach was applied, carried up to $200,000 \mathrm{~cm}^{-1}$ across 1,000 bins. Simulations were carried out for around 5,000 collisions, allowing sufficient time for collisional deactivation of the excited ion population. 

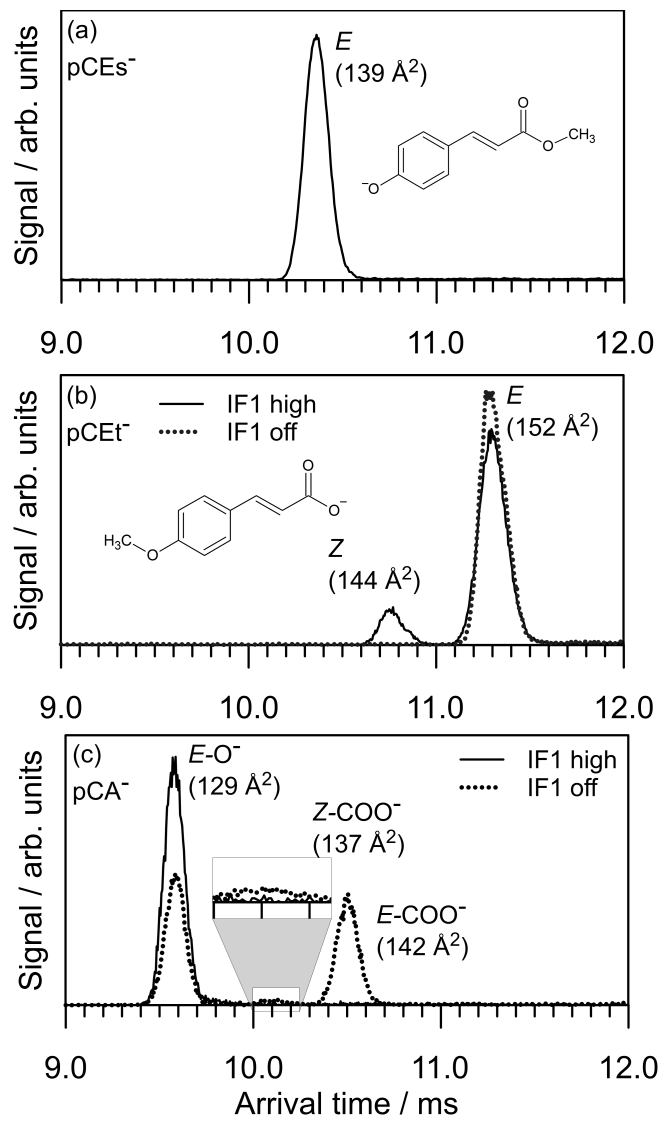

Figure 2: ATDs for (a) $\mathrm{pCEs}^{-}$, (b) $\mathrm{pCEt}^{-}$and (c) $\mathrm{pCA}^{-}$. Solid and dashed traces correspond respectively, to high and no $\mathrm{RF}$ drive voltage applied to the source ion funnel. Measured collision cross-sections for the isomers associated with each peak are given in the figure (estimated errors are $\pm 5 \AA^{2}$ ).

\section{Results and discussion}

\section{ATDs and isomer assignments}

The ATDs for $\mathrm{pCEs}^{-}, \mathrm{pCEt}^{-}$and $\mathrm{pCA}^{-}$are shown in Figure 2. We first consider the methylated molecules as they each have only a single deprotomer and can only exist as $E$ or $Z$ isomers. The ATD for $\mathrm{pCEs}^{-}$(Figure 2a) exhibits a single peak irrespective of electrospray or source conditions. This peak was assigned to the $E$ isomer since it is predicted to be $25 \mathrm{~kJ} \mathrm{~mol}^{-1}$ more stable than the $Z$ isomer in the gas phase (Table 1 ). The ATD for pCEt ${ }^{-}$ (Figure 2b) displays two peaks, with relative intensities that were influenced by collisional excitation of the ions in IF1 prior to injection into the drift region. The calculated energies 
Table 1: Relative energies of isomers and deprotomers (in $\mathrm{kJ} \mathrm{mol}^{-1}$ ) at the FNOCCSD(T)/GEN level of theory (CCSD(T)/GEN values in parentheses) with zero-point corrections and calculated collision cross-sections $\left(\Omega_{c}\right.$ in $\left.\AA^{2}\right)$. $\mathrm{O}^{-}$and $\mathrm{COO}^{-}$indicate phenoxide and carboxylate deprotomers, respectively. All calculation used $\omega$ B97X-D/aug-cc-pVTZ optimized geometries.

\begin{tabular}{ccccc}
\hline Species & $E$ & $Z$ & $\Omega_{c}(E)$ & $\Omega_{c}(Z)$ \\
\hline $\mathrm{pCEs}^{-}$ & 0 & $25^{a}$ & 142 & 140 \\
$\mathrm{pCEt}^{-}$ & $40^{a}$ & $45^{a}$ & 153 & 147 \\
$\mathrm{pCA}^{-}\left(\mathrm{O}^{-}\right)$ & 0 & $26(26)^{b}$ & 134 & 133 \\
$\mathrm{pCA}^{-}\left(\mathrm{COO}^{-}\right)$ & $41(42)^{b}$ & $46(47)^{b}$ & 146 & 140 \\
${ }^{a}$ Energy relative to $E$-pCEs & \\
&
\end{tabular}

and collision cross-sections given in Table 1 support assignment of the later, more intense ATD peak to $E$-pCEt ${ }^{-}$and the earlier ATD peak to $Z$-pCEt ${ }^{-}$, which is predicted to lie only $5 \mathrm{~kJ} \mathrm{~mol}^{-1}$ higher in energy. With no drive voltage applied to IF1 (IF1 off), only a single peak was observed which can be assigned to $E$-pCEt ${ }^{-}$because a pure sample of this isomer was electrosprayed. In contrast, with high RF drive voltage applied to the first ion funnel (IF1 high), violent collisions between the ions and buffer gas molecules convert some $E$-pCEt ${ }^{-}$ to $Z$-pCEt ${ }^{-}{ }^{44,45,68}$ Following injection into the drift region, the ions should cool quickly through buffer gas collisions, resulting in a non-equilibrium distribution of isomers, with the extent of reversion to the more stable form depending on the ground state isomerization barriers and rates. See Ref. 69 for another ion mobility study of $E$ and $Z$ isomers that differ in energy by $5 \mathrm{~kJ} \mathrm{~mol}^{-1}$.

The ATD for $\mathrm{pCA}^{-}$(Figure 2c) exhibits three peaks that can be connected to the $E$ $\mathrm{pCA}^{-}\left(\mathrm{O}^{-}\right), Z$-pCA- $\left(\mathrm{COO}^{-}\right)$and $E$ - $\mathrm{pCA}^{-}\left(\mathrm{COO}^{-}\right)$isomers based on their calculated cross-sections and relative energies (Table1), variation of peak intensities with ion funnel RF drive voltage, and their photoresponses (discussed in the next section). Note that the $E$-pCA ${ }^{-}\left(\mathrm{O}^{-}\right)$and $Z$-pCA ${ }^{-}\left(\mathrm{O}^{-}\right)$isomers are predicted to have near identical collision crosssections (see Table 1), potentially making them difficult to separate in the IMS.

We considered the possible contributions of rotamers (conformations involving torsion about the single bonds connecting the alkene tail to the carboxylic group or the aromatic 
ring). For the $E-\mathrm{pCA}^{-}\left(\mathrm{COO}^{-}\right)$and $Z-\mathrm{pCA}^{-}\left(\mathrm{COO}^{-}\right)$isomers, DFT calculations at the $\omega B$ 97X-D/aug-cc-pVDZ level gave barriers of $11 \mathrm{~kJ} \mathrm{~mol}^{-1}$ and $22 \mathrm{~kJ} \mathrm{~mol}^{-1}$, respectively, for internal rotation of the aromatic ring. Internal rotation of the $-\mathrm{COO}^{-}$group does not lead to conformational change. RRKM theory calculations indicate that the aromatic ring undergoes rapid internal rotation at $300 \mathrm{~K}$, with rate coefficients of $3.4 \times 10^{10} \mathrm{~s}^{-1}$ for $E$-pCA ${ }^{-}$ $\left(\mathrm{COO}^{-}\right)$and $8.7 \times 10^{8} \mathrm{~s}^{-1}$ for $Z-\mathrm{pCA}^{-}\left(\mathrm{COO}^{-}\right)$. Because the timescale for internal rotation is much less than the drift time ( $\approx 10 \mathrm{~ms})$ each carboxylate deprotomer ATD peak will represent contributions from the single-bond rotamers. ${ }^{70}$ Predicted barriers $(\omega \mathrm{B} 97 \mathrm{XD} /$ aug-cc-pVDZ level of theory) for internal rotation about single bonds in $E$-pCA- $\left(\mathrm{O}^{-}\right)$are larger, at $55 \mathrm{~kJ} \mathrm{~mol}^{-1}$ for torsion about the bond connecting the alkene tail to the aromatic ring (leading to no conformational change) and $66 \mathrm{~kJ} \mathrm{~mol}^{-1}$ for internal rotation of the $-\mathrm{CO}_{2} \mathrm{H}$ group, with the rate coefficient for the latter motion at $300 \mathrm{~K}$ calculated as $1.5 \times 10^{1} \mathrm{~s}^{-1}$. Therefore, two non-interconverting $E$ - $\mathrm{pCA}^{-}\left(\mathrm{O}^{-}\right)$rotamers, with energies predicted to differ by only $2 \mathrm{~kJ} \mathrm{~mol}^{-1}$, may exist in the drift region. However, both rotamers have calculated collision cross-sections of $134 \AA^{2}$, and may be difficult to distinguish using IMS.

\section{Action spectra of $E$-pCEs ${ }^{-}, E-$ pCA $^{-}\left(\mathrm{O}^{-}\right)$and $E$-pCEt ${ }^{-}$}

The effect of light on mobility-selected $E$-pCEs ${ }^{-}, E$-pCA ${ }^{-}\left(\mathrm{O}^{-}\right)$and $E$-pCEt ${ }^{-}$anions is illustrated in Figure 3 where difference or 'photoaction' ATDs (light-on ATD - light-off ATD) are shown in (a) and (b) while action spectra (photodetachment or photodepletion yield plotted against wavelength) are shown in the (c) and (d). The E-pCEs ${ }^{-}$anion undergoes photodetachment over the $350-460 \mathrm{~nm}$ range, a process followed by monitoring the yield of $\mathrm{SF}_{6}{ }^{-}$(Figure 3a). The $\mathrm{SF}_{6}{ }^{-}$signal balances the photodepletion of the parent $E$-pCEs ${ }^{-}$ signal for light fluences $<0.5 \mathrm{~mJ} \mathrm{~cm}^{-1}$ pulse $^{-1}$ at all wavelengths with no evidence for photoisomerization or photodissociation, proving that photodetachment is the dominant process. The $E$-pCA ${ }^{-}\left(\mathrm{O}^{-}\right)$isomer (gray action spectrum in Figure 3c) exhibits similar behaviour to $E$-pCEs ${ }^{-}$, again with no evidence for photodissociation or photoisomerization, and with 

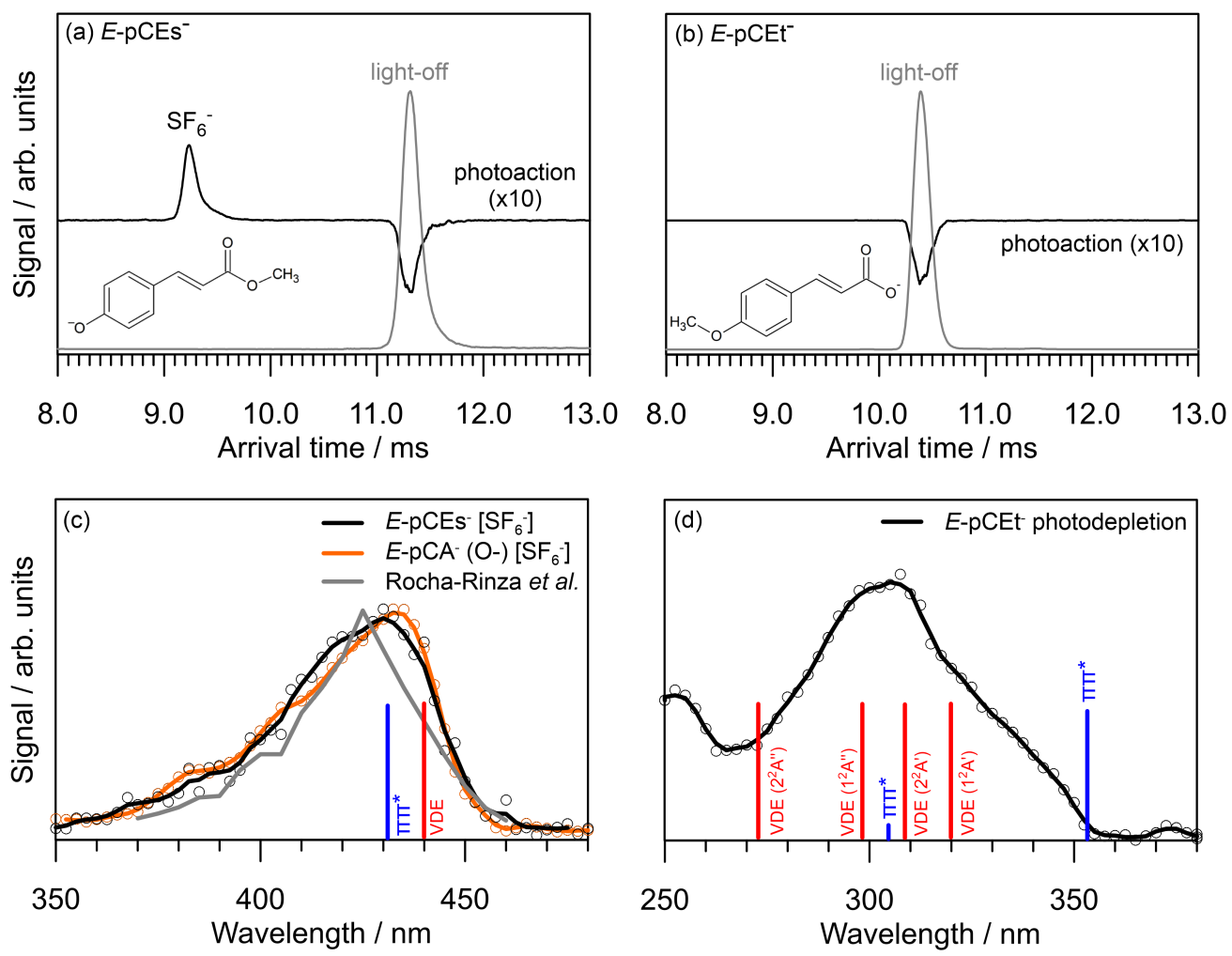

Figure 3: (a) Photoaction ATD corresponding to the difference of light-on and light-off ATD for $E$-pCEs ${ }^{-}$at $420 \mathrm{~nm}$ obtained with $\mathrm{N}_{2}$ and trace $\mathrm{SF}_{6}$ buffer gas. The quadrupole mass filter was used as an ion guide to transmit the parent anion and $\mathrm{SF}_{6}{ }^{-}$. (b) Photoaction ATD for $E$-pCEt ${ }^{-}$at $300 \mathrm{~nm}$ obtained with $\mathrm{N}_{2}$ buffer gas. (c) Action spectra for $E$-pCA- $\left(\mathrm{O}^{-}\right)$, $E$-pCEs ${ }^{-}$and $E$-pCEs ${ }^{-}$from Ref. 36 (gray). (d) Action spectrum for $E$-pCEt ${ }^{-}$. There was no discernible photoresponse for $E$-pCEt ${ }^{-}$over the $380-480 \mathrm{~nm}$ range. In the action spectra, blue vertical bars denote vertical $\pi \pi^{*}$ transitions of $E$-pCEs ${ }^{-}$and $E$-pCEt ${ }^{-}$calculated at the EOM-CC3/aug-cc-pVDZ level whereas red vertical bars denote vertical electron detachment energies (VDE) calculated at the EOM-IP-CCSD/aug-cc-pVDZ level. Note that ATD peaks in (a) and (b) are shifted compared to those in Figure 2 due to a slight change in buffer gas pressure (measurements performed on different days).

with the EOM-CC3/aug-cc-pVDZ calculated vertical excitation energy (VEE) for the lowest energy $\pi \pi^{*}$ state and the EOM-IP-CCSD/aug-cc-pVDZ calculated vertical detachment energy (VDE) in Table 2, which correspond to wavelengths of 431 and $440 \mathrm{~nm}$, respectively. Note that the calculated VDE for $E$-pCEs ${ }^{-}$agrees with the value derived from photoelectron spectroscopy $(2.8 \pm 0.1 \mathrm{eV}$ or $\approx 440 \mathrm{~nm}) .{ }^{40}$ Results for the $E$-pCA ${ }^{-}\left(\mathrm{O}^{-}\right)$isomer are very similar to those for $E$-pCEs ${ }^{-}$(see Table 2). Our calculated VEE values for $E$-pCA- $\left(\mathrm{O}^{-}\right)$ lie below the values calculated by Zuev et al. ${ }^{59}$ at the EOM-CCSD $/ 6-31+\mathrm{G}(\mathrm{d}, \mathrm{p})$ and EOM- 
$\mathrm{CC} 3 / 6-31+\mathrm{G}(\mathrm{d}, \mathrm{p})$ levels of theory by $\approx 0.2$ and $\approx 0.1 \mathrm{eV}$, respectively (see the Supporting Information for discussion).

The photoaction ATD and photodepletion action spectrum for $E$-pCEt ${ }^{-}$are shown in Figure $3 \mathrm{~b}$ and d, respectively. The photoaction ATD only shows evidence for photodepletion, most probably due to photodetachment since there was no sign of photofragments when the quadrupole mass filter was set to transmit all masses (note that $m / z<80$ have low transmission through the instrument). It was not possible to scavenge the photodetached electrons with $\mathrm{SF}_{6}$ at excitation wavelengths shorter than $350 \mathrm{~nm}$ because of interference from photoelectrons generated by light striking the drift electrodes. The $E$-pCEt ${ }^{-}$action spectrum (photodepletion yield plotted against wavelength) has a peak at $305 \mathrm{~nm}$ and a profile consistent with the calculated VDEs (Table 2). Again, there is no evidence for photoisomerization in the region of the predicted $\pi \pi^{*}$ absorptions (353 and $305 \mathrm{~nm}$ ). Unfortunately, we were unable to obtain an action spectrum for $Z$-pCEt ${ }^{-}$because of low ion signal.

\section{Ground state reversion}

The fact that photodepletion of the $E$-pCEs ${ }^{-}$and $E$-pCA ${ }^{-}\left(\mathrm{O}^{-}\right)$ions is matched by generation of $\mathrm{SF}_{6}{ }^{-}$(for example see Figure 3a) indicates at first sight that autodetachment is more rapid than photoisomerization. However, it is possible the molecules undergo rapid isomerization but that the nascent, energized $Z$ photoisomers statistically revert to the original $E$ isomers on the ground state potential energy surface before being stabilized through collisional deactivation in the drift region. To explore this issue we computed statistical rates for $Z \rightarrow E$ isomerization on the electronic ground state surface using a master equation approach that combined coupled Rice-Ramsperger-Kassel-Marcus (RRKM) rates for isomerization and collisional energy transfer using a Langevin ion-molecule collision model. ${ }^{45,46,71}$ Computed RRKM isomerization rates, $k(E)$, for $Z$-pCEs ${ }^{-}$and $Z$-pCA ${ }^{-}\left(\mathrm{O}^{-}\right)$plotted as a function of internal energy are shown in Figure $4 \mathrm{a}$ and b, respectively. Given that with 6 Torr $\mathrm{N}_{2}$ buffer gas the collision rate is $\sim 10^{9} \mathrm{~s}^{-1}$ and hundreds of collisions are required 

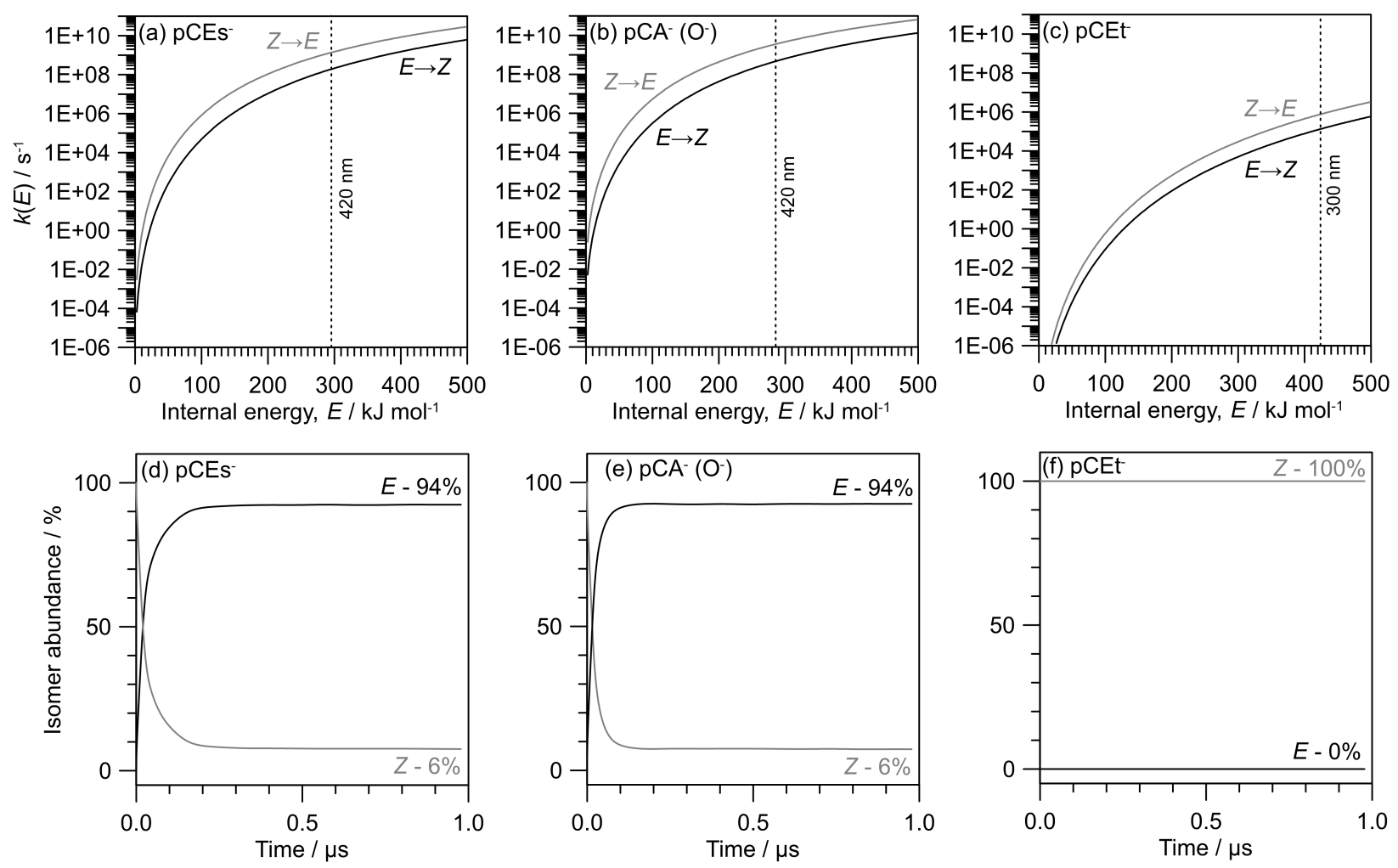

Figure 4: Statistical RRKM isomerisation rates $[k(E)]$ for $Z \rightarrow E$ (gray) and $E \rightarrow Z$ (black) isomerization: (a) $\mathrm{pCEs}^{-}$, (b) $\mathrm{pCA}^{-}\left(\mathrm{O}^{-}\right)$, (c) $\mathrm{pCEt}^{-}$. Master equation modelling of isomer abundances with time following prompt formation of the $Z$ isomer and assuming (d) $E=291 \mathrm{~kJ} \mathrm{~mol}^{-1}$ for $Z$-pCEs${ }^{-}$, (e) $285 \mathrm{~kJ} \mathrm{~mol}^{-1}$ for $Z$-pCA ${ }^{-}\left(\mathrm{O}^{-}\right)$and (f) $425 \mathrm{~kJ} \mathrm{~mol}^{-1}$ for $Z$-pCEt ${ }^{-}$. In (d) and (e), statistical $Z \rightarrow E$ isomerization is compete within $\approx 200$ and $100 \mathrm{~ns}$, respectively.

to quench the internal energy derived from a single visible photon, statistical isomerization should occur when $k(E)>10^{6}-10^{7} \mathrm{~s}^{-1}$. For $Z$-pCEs ${ }^{-}$with $E=291 \mathrm{~kJ} \mathrm{~mol}^{-1}$ of internal energy, $k_{Z \rightarrow E}(E)=1.78 \times 10^{8} \mathrm{~s}^{-1}$, whereas for $Z-\mathrm{pCA}^{-}\left(\mathrm{O}^{-}\right)$with $E=285 \mathrm{~kJ} \mathrm{~mol}^{-1}$ of internal energy, $k_{Z \rightarrow E}(E)=4.63 \times 10^{8} \mathrm{~s}^{-1}$. In each case, the assumed initial energy corresponds to the energy imparted from a $420 \mathrm{~nm}$ photon (wavelength of peak response in the action spectrum) plus the initial average thermal energy of $E$ isomers at $298 \mathrm{~K}$, and is corrected for the electronic energy difference between the $Z$ and $E$ isomers. The large $k_{Z \rightarrow E}(E)$ rate coefficients suggest there should be efficient $Z \rightarrow E$ reversion in both cases. For example, the master equation modelling (Figure 4d) suggests $94 \%$ of nascent $Z$-pCEs ${ }^{-}$ isomers revert to the $E$ isomer. The situation is similar for $Z$-pCA- $\left(\mathrm{O}^{-}\right)$for which master 
equation modelling suggests near complete $Z \rightarrow E$ reversion after $100 \mathrm{~ns}$ (see Figure $4 \mathrm{e}$ ). We conclude that, if formed, nascent $Z$-pCEs ${ }^{-}$and $Z$ - $\mathrm{pCA}^{-}\left(\mathrm{O}^{-}\right)$isomers are likely to rapidly convert back to their $E$ isomers and will not be observed in the present experiments. Therefore, we cannot certainly conclude from the ion mobility data that photodetachment is the only process ensuing following photoexcitation of the $\pi \pi^{*}$ transition as it is possible that some fraction of the excited population undergoes rapid $E \rightarrow Z$ somerization, but that the energized $Z$ isomers subsequently revert back to the more stable $E$ isomeric form.

According to the modelling, the situation differs for $E$-pCEt ${ }^{-}$for which the photoaction ATD (Figure 3b) again shows no evidence for $E \rightarrow Z$ photoisomerization over the expected wavelength range for the $\pi \pi^{*}$ transition despite the modelling suggesting that nascent $Z$ $\mathrm{pCEt}^{-}$with $E=425 \mathrm{~kJ} \mathrm{~mol}^{-1}$ of internal energy should be stabilized through collisions (see Figure 4f). We conclude that $E$-pCEt ${ }^{-}$probably does not photoisomerize in the visible or near-UV in the gas phase.

\section{Action spectra of $E-\mathrm{pCA}^{-}\left(\mathrm{COO}^{-}\right)$and $Z$-pCA ${ }^{-}\left(\mathrm{COO}^{-}\right)$}

The effect of light on mobility-selected $E$-pCA ${ }^{-}\left(\mathrm{COO}^{-}\right)$and $Z$-pCA ${ }^{-}\left(\mathrm{COO}^{-}\right)$isomers is apparent from the photoaction ATDs and action spectra shown in Figure 5. Photoexcitation of the $E-\mathrm{pCA}^{-}\left(\mathrm{COO}^{-}\right)$deprotomer over the $290-385 \mathrm{~nm}$ range leads to formation of two photoisomers. The major photoisomer has a collision cross section close to that of the phenoxide deprotomer $E$-pCA- $\left(\mathrm{O}^{-}\right)$(within $\left.\pm 0.3 \AA^{2}\right)$ indicating the occurrence of photoinduced proton transfer from one end of the molecule to the other. The experimental procedure for determining the photoisomer's collision cross-section is outlined in the SI.

The minor photoisomer has a collision cross-section lying between those of the phenoxide and carboxylate deprotomers, and which, on the basis of arguments presented below, is assigned to the E-keto-pCA ${ }^{-}$isomer (see structure in Figure 1). The ratio of the yields for the E-keto-pCA${ }^{-}$and $E$-pCA $\mathrm{pC}^{-}\left(\mathrm{O}^{-}\right)$isomers is $0.07 \pm 0.01$ (6 Torr $\mathrm{N}_{2}$ buffer gas). No corresponding processes were observed for $E$-pCEt ${ }^{-}$(Figure $3 \mathrm{~b}$ ), indicating that replacing 
the alcohol functional group by an ether blocks both photoisomerization processes.

Action spectra associated with formation of the $E$-keto-pCA ${ }^{-}$and $E$-pCA $\mathrm{pA}^{-}\left(\mathrm{O}^{-}\right)$photoisomers are similar (Figure 5c), with the main band spanning the 290-385 nm range and a maximum response at $360 \mathrm{~nm}$. The action spectrum is consistent with the lowest energy EOM-CC3/aug-cc-pVDZ VEE for $E$-pCA- $\left(\mathrm{COO}^{-}\right)$, which corresponds to a wavelength of $348 \mathrm{~nm}$. The VEE for $E$-pCA ${ }^{-}\left(\mathrm{COO}^{-}\right)$calculated by Zuev et al. ${ }^{59}$ at the EOM-CC3/6$31+\mathrm{G}(\mathrm{d}, \mathrm{p})$ level of theory at $4.50 \mathrm{eV}$ (corresponding to a wavelength of $276 \mathrm{~nm}$ ) lies $\approx 0.9 \mathrm{eV}$ above the EOM-CC3/aug-cc-pVDZ value (see the Supporting Information for further com-
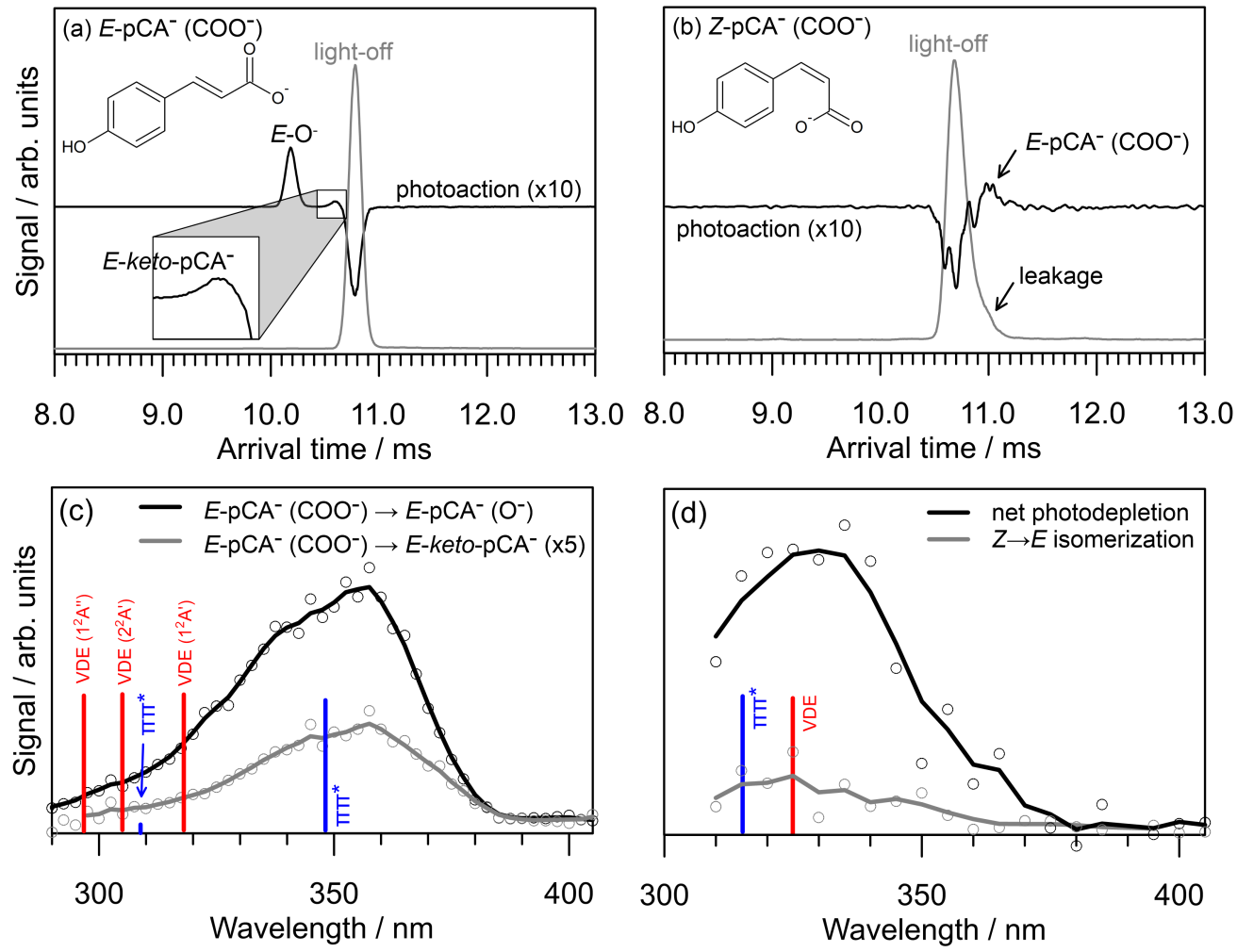

Figure 5: Photoaction ATDs corresponding to the difference of light-on and light-off ATDs for (a) $E-\mathrm{pCA}^{-}\left(\mathrm{COO}^{-}\right)$at $355 \mathrm{~nm}$ and (b) $Z-\mathrm{pCA}^{-}\left(\mathrm{COO}^{-}\right)$at $320 \mathrm{~nm}$. Action spectra are shown in (c) for $E$-pCA ${ }^{-}\left(\mathrm{COO}^{-}\right)$and $(\mathrm{d})$ for $Z$ - $\mathrm{pCA}^{-}\left(\mathrm{COO}^{-}\right)$. Blue vertical bars denote vertical $\pi \pi^{*}$ transitions calculated at the EOM-CC3/aug-cc-pVDZ level and red vertical bars denote vertical electron detachment energies (VDE) calculated at the EOM-IP-CCSD/augcc-pVDZ level. Note, the action spectrum for $Z$-pCA- $\left(\mathrm{COO}^{-}\right)$shown in (d), was recorded with the laser pulse timed to interact with the leading edge of the ion packet to avoid irradiating $E-\mathrm{pCA}^{-}\left(\mathrm{COO}^{-}\right)$ions leaking through the second ion gate. The ATD peaks are shifted compared to those in Figure 2 due to a slight change in buffer gas pressure (measurements performed on different days). 
parisons and discussion).

The absorption spectra for $E$-pCA ${ }^{-}\left(\mathrm{COO}^{-}\right)$and $E$-pCEt ${ }^{-}$are expected to be quite similar - electronic structure calculations predict a $\pi \pi^{*}$ transition at $\approx 350 \mathrm{~nm}$ in both cases (see Figures 5c and 3d and Table 2). However, the experimental action spectra of E-pCA$\left(\mathrm{COO}^{-}\right)$and $E$-pCEt ${ }^{-}$shown in Figure $5 \mathrm{c}$ and Figure $3 \mathrm{~d}$ differ substantially, possibly reflecting a dependence of the photo-yield on wavelength. In the case of $E$-pCEt ${ }^{-}$, the action spectrum was obtained by monitoring photodepletion (presumably due to electron detachment), with the peak of the observed band occurring at $305 \mathrm{~nm}$, close to the lowest calculated vertical detachment energy (corresponding to $320 \mathrm{~nm}$ ). Absorption of photons with wavelength exceeding $\approx 320 \mathrm{~nm}$ may not provide $E$-pCEt ${ }^{-}$with sufficient energy to detach an electron leading to diminished signal intensity in this region. In the case of $E$-pCA $\mathrm{pA}^{-}\left(\mathrm{COO}^{-}\right)$, the action spectrum was recorded by monitoring photoisomerization, a process whose barrier is predicted to lie below the photon energy for wavelengths shorter than $\approx 380 \mathrm{~nm}$. Therefore, it is possible that the action spectrum of $E$-pCA- $\left(\mathrm{COO}^{-}\right)$better resembles the actual absorption spectrum. It is also worth emphasizing that the energized molecules are subject to quenching through collisions, potentially suppressing slow photoisomerization, dissociation and electron detachment processes, and possibly influencing the shape of the action spectrum if the photoproduct yield depends on wavelength.

For $E-\mathrm{pCA}^{-}\left(\mathrm{COO}^{-}\right)$, photodepletion of the parent ions was balanced by formation of the two photoisomers across the entire wavelength range, implying that photodetachment was negligible. Assignment of the major photoisomer to $E$-pCA- $\left(\mathrm{O}^{-}\right)$was supported by measurements described in the Supporting Information which show that the major photoisomer has an arrival time matching that of $E-\mathrm{pCA}^{-}\left(\mathrm{O}^{-}\right)$to within $0.02 \mathrm{~ms}$ and that their collision cross-sections differ by no more than $0.3 \AA^{2}$. Evidence for assignment of the minor photoisomer to E-keto-pCA ${ }^{-}$and development of an interconversion mechanism are outlined in the following two sections.

For $Z$-pCA ${ }^{-}\left(\mathrm{COO}^{-}\right)$, the photoaction ATD shown in Figure $5 \mathrm{~b}$ provides evidence for 
photoisomerization to a slower isomer with a collision cross-section consistent with its assignment to $E$-pCA ${ }^{-}\left(\mathrm{COO}^{-}\right)$. There was an overall loss of ions which is thought to result from photodetachment rather than photodissociation as no fragment ions were observed, although it is possible that low mass $(m / z<90)$ ions with poor transmission though the quadrupole mass filter were formed. We were unable to perform measurements in the $\mathrm{N}_{2}+$ $\mathrm{SF}_{6}$ buffer gas mixture with $Z$-pCA- $\left(\mathrm{COO}^{-}\right)$due to low ion throughput and background photoelectrons from scattered light striking metal drift electrodes. The photoisomerization and net photodepletion (total photodepletion - photoisomerization) action spectra for $Z$ $\mathrm{pCA}^{-}\left(\mathrm{COO}^{-}\right)$, shown in Figure $5 \mathrm{~d}$, are consistent with the calculated $\pi \pi^{*} \mathrm{VEE}$ and VDE values (Table 2), which correspond to wavelengths of 314 and $325 \mathrm{~nm}$, respectively. The photoisomerization action spectrum has a maximum at $\approx 330 \mathrm{~nm}$, a blue-shift of around $30 \mathrm{~nm}$ compared to the $E$-pCA ${ }^{-}\left(\mathrm{COO}^{-}\right)$action spectrum.

In summary, $E$ and $Z$ isomers of $\mathrm{pCA}^{-}\left(\mathrm{COO}^{-}\right)$undergo distinct processes following photoexcitation. Whereas $E$-pCA $\mathrm{pC}^{-}\left(\mathrm{COO}^{-}\right)$appears to undergo tautomerism and proton transfer, $Z$-pCA ${ }^{-}\left(\mathrm{COO}^{-}\right)$undergoes $Z \rightarrow E$ isomerization and probably electron detachment with no evidence for tautomerism or proton transfer either through an excited state process or following internal conversion to the ground state.

\section{Action spectroscopy of $E$-keto-pCA ${ }^{-}$}

To help assign the minor photoisomer produced from $E-\mathrm{pCA}^{-}\left(\mathrm{COO}^{-}\right)$and to investigate its possible involvement in the $E$-pCA $\mathrm{pC}^{-}\left(\mathrm{COO}^{-}\right) \rightarrow E$-pCA ${ }^{-}\left(\mathrm{O}^{-}\right)$transformation, we produced the minor photoisomer apparent in Figure 5a by intercepting electrosprayed ions with a pulse of $355 \mathrm{~nm}$ light (Quantel Big Sky Nd:YAG, $40 \mathrm{~Hz}$ ) immediately after their injection into the drift region (IMS1). ${ }^{46,72}$ The target molecules were then mobility-separated in IMS1, selected with the Bradbury-Nielsen ion gate, and exposed to a pulse of tunable light from the OPO. A photoaction ATD and photoisomerization action spectrum of the putative E-keto-pCA ${ }^{-}$ ions are shown in Figure6, showing formation of a photoisomer that has a collision cross- 

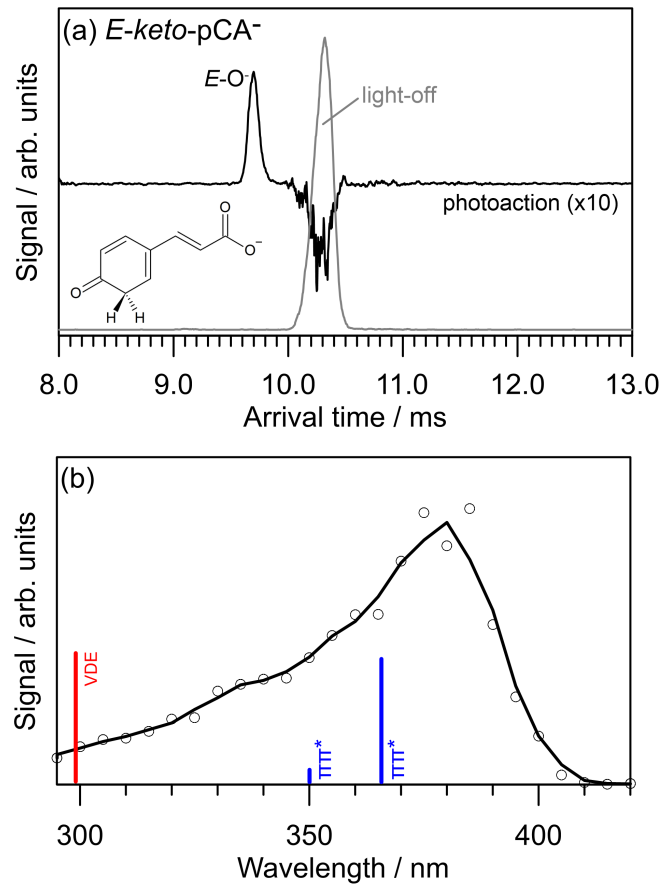

Figure 6: Photoresponse of the putative E-keto-pCA- photoisomer. (a) 'light-off' and photoaction ATDs at $355 \mathrm{~nm}$. The photodepletion peak is noisy because it corresponds to the difference between a laser-on and laser-off signals and there was relatively low ion throughput. (b) Action spectrum for E-keto-pCA ${ }^{-}$recorded by monitoring the $E$-pCA ${ }^{-}\left(\mathrm{O}^{-}\right)$photoisomer as a function of wavelength. Calculated VEEs (EOM-CC3/aug-cc-pVDZ) and VDE (EOM-IP-CCSD/aug-cc-pVDZ) are indicated by blue and red bars, respectively.

section consistent with its assignment to $E-\mathrm{pCA}^{-}\left(\mathrm{O}^{-}\right)$. The photodepletion signal was balanced by the photoisomer signal for all wavelengths, indicating minimal photodissociation or photodetachment. The action spectrum (Figure 6b) has a maximum at $380 \mathrm{~nm}$ and is consistent with the calculated VEEs for E-keto-pCA- ${ }^{-}$, which correspond to wavelengths of 366 and $350 \mathrm{~nm}$ (Table 2). The consistency of the measured action spectrum and theoretical predictions support assignment of the minor photoisomer from $E$-pCA $\mathrm{pA}^{-}\left(\mathrm{COO}^{-}\right)$to the E-keto-pCA ${ }^{-}$species.

\section{Proton transfer mechanism}

As outlined above, our measurements suggest that the $E-\mathrm{pCA}^{-}\left(\mathrm{COO}^{-}\right)$photoisomerizes to produce $E$-pCA ${ }^{-}\left(\mathrm{O}^{-}\right)$through intramolecular proton transfer, hitherto an unknown pro- 
cess for a cinnamate-based chromophore. Further measurements suggest E-keto-pCA ${ }^{-}$is probably an intermediate in the proton transfer process whereas $Z$-pCA ${ }^{-}\left(\mathrm{COO}^{-}\right)$plays no role. Initially, two mechanisms for proton transfer come to mind: (i) an initial excited state rearrangement, possibly followed by ground state rearrangements before the vibrationally energized product ions cool through buffer gas collisions, or (ii) $\mathrm{S}_{1} \rightarrow \mathrm{S}_{0}$ internal conversion producing vibrationally energized $E$-pCA ${ }^{-}\left(\mathrm{COO}^{-}\right)$molecules followed by statistical rearrangements. Although the present experiments were unable to directly probe mechanistic details, the proton transfer reaction must occur more rapidly than collisional quenching of vibrational energy in the drift region (expected to occur over hundreds of nanoseconds).

To help eludicate the proton transfer mechanism, we computed potential energy surfaces linking the isomers and modelled the interconversions using a coupled master equation approach. The proposed minimum energy pathway is summarized in Figure 7a and b. We propose that the first step involves a barrierless enol-keto tautomerism involving passage through a conical intersection. This proposal is based on calculated potential energy surfaces for enol-keto tautomerization (Figure 7c) in which the proton on the hydroxide group was displaced to achieve the E-keto-pCA ${ }^{-}$isomer while the rest of the molecule was allowed to geometrically relax. The minimum energy pathway in Figure 7c suggests that there is a barrierless curve crossing at an $\mathrm{O}-\mathrm{H}$ bond distance of $\approx 1.4 \AA$, implying the existence a conical intersection seam. Similar enol-keto phototautomerisms are well known for several related molecules containing phenolic groups dissolved in non-protic solvents ${ }^{73-76}$ and involve similar potential energy surfaces. The possibility of a ground state enol-keto tautomerism, which could occur after internal conversion to $\mathrm{S}_{0}$, was ruled out on the basis of master equation modelling, which suggested that collisional cooling of photoactivated $E$-pCA ${ }^{-}\left(\mathrm{COO}^{-}\right)$ occurs before isomerization (assuming initial energy derived from a $360 \mathrm{~nm}$ photon).

Following enol-keto phototautomerism via passage through a conical intersection, the reaction is postulated to proceed on the ground state potential energy surface as summarized in Figure $7 \mathrm{a}$ and $\mathrm{b}$. The proposed pathway involves cyclization of the E-keto-pCA- isomer, 
ring-opening to form $Z$-keto- $\mathrm{pCA}^{-}$, a ground state proton transfer to give $Z$ - $\mathrm{pCA}^{-}\left(\mathrm{O}^{-}\right)$, and finally $Z \rightarrow E$ isomerization to yield $E$ - $\mathrm{pCA}^{-}\left(\mathrm{O}^{-}\right)$. Master equation modelling of this pathway (Figure 7d) started from E-keto-pCA- and assumed initial energy derived from a $360 \mathrm{~nm}$ photon. The modelling suggested $\approx 90 \%$ of E-keto-pCA ${ }^{-}$statistically isomerized to $E$-pCA ${ }^{-}\left(\mathrm{O}^{-}\right)$after $\approx 15 \mu \mathrm{s}$, while $\approx 6 \%$ of the population is collisionally stabilized as E-keto$\mathrm{pCA}^{-}$. These abundances are consistent with the experimental E-keto-pCA ${ }^{-}$to $E$-pCA ${ }^{-}$ $\left(\mathrm{O}^{-}\right)$branching ratio of $0.07 \pm 0.01$. Interestingly, the modelling also suggested stabilization of a small amount of $Z-\mathrm{pCA}^{-}\left(\mathrm{O}^{-}\right)$. However, as noted earlier, distinguishing the $E$ and $Z$-pCA- $\left(\mathrm{O}^{-}\right)$isomers in $\mathrm{N}_{2}$ buffer gas may be difficult given they are predicted to have similar collision cross-sections (Table 1).

For completeness, the minimum energy proton transfer pathway involving $Z$-pCA ${ }^{-}\left(\mathrm{COO}^{-}\right)$ is shown in gray in Figure 7b. As outlined in the previous section, this pathway can be ruled out because the photoaction ATD for $Z-\mathrm{pCA}^{-}\left(\mathrm{COO}^{-}\right)$(Figure $\left.5 \mathrm{~b}\right)$ showed no evidence for isomerization to $E$-pCA $\mathrm{pC}^{-}\left(\mathrm{O}^{-}\right)$, and because master equation modelling for energized $E$-pCA ${ }^{-}\left(\mathrm{COO}^{-}\right)$indicated that ground state $E \rightarrow Z$ isomerization does not occur due to the large barriers. However, it is worth noting that the $Z$ - $\mathrm{pCA}^{-}\left(\mathrm{COO}^{-}\right) \rightarrow Z$ - $\mathrm{pCA}^{-}$ $\left(\mathrm{O}^{-}\right)$transformation (which was not observed) has a lower calculated barrier than $Z$-pCA ${ }^{-}$ $\left(\mathrm{COO}^{-}\right) \rightarrow E$ - $\mathrm{pCA}^{-}\left(\mathrm{COO}^{-}\right)$isomerization (which was observed). This implies that $E$ $\mathrm{pCA}^{-}\left(\mathrm{COO}^{-}\right)$formed through photoexcitation of $Z$ - $\mathrm{pCA}^{-}\left(\mathrm{COO}^{-}\right)$in Figure $5 \mathrm{~b}$ results from passage through a conical intersection rather than internal conversion followed by statistical isomerization (otherwise $Z$ - $\mathrm{pCA}^{-}\left(\mathrm{O}^{-}\right)$would be observed). The different relative importances of phototautomerism, photodetachment and photoisomerization for $E$-pCA ${ }^{-}$ $\left(\mathrm{COO}^{-}\right)$and $Z-\mathrm{pCA}^{-}\left(\mathrm{COO}^{-}\right)$, presumably reflects differences in the topology of the excited state PESs and couplings with lower PESs in the neighbourhood of their respective Franck-Condon regions. 

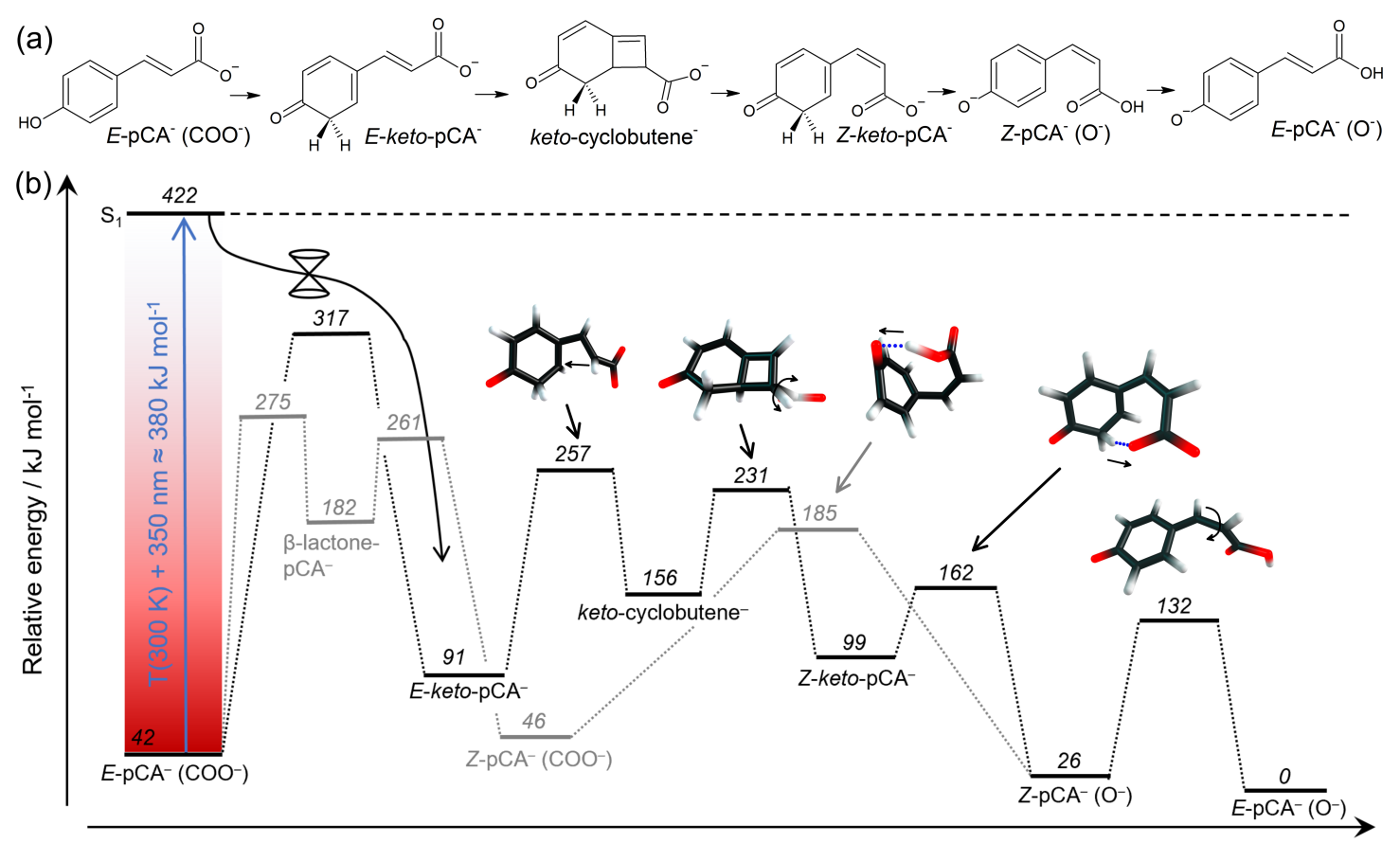

Proton transfer reaction co-ordinate
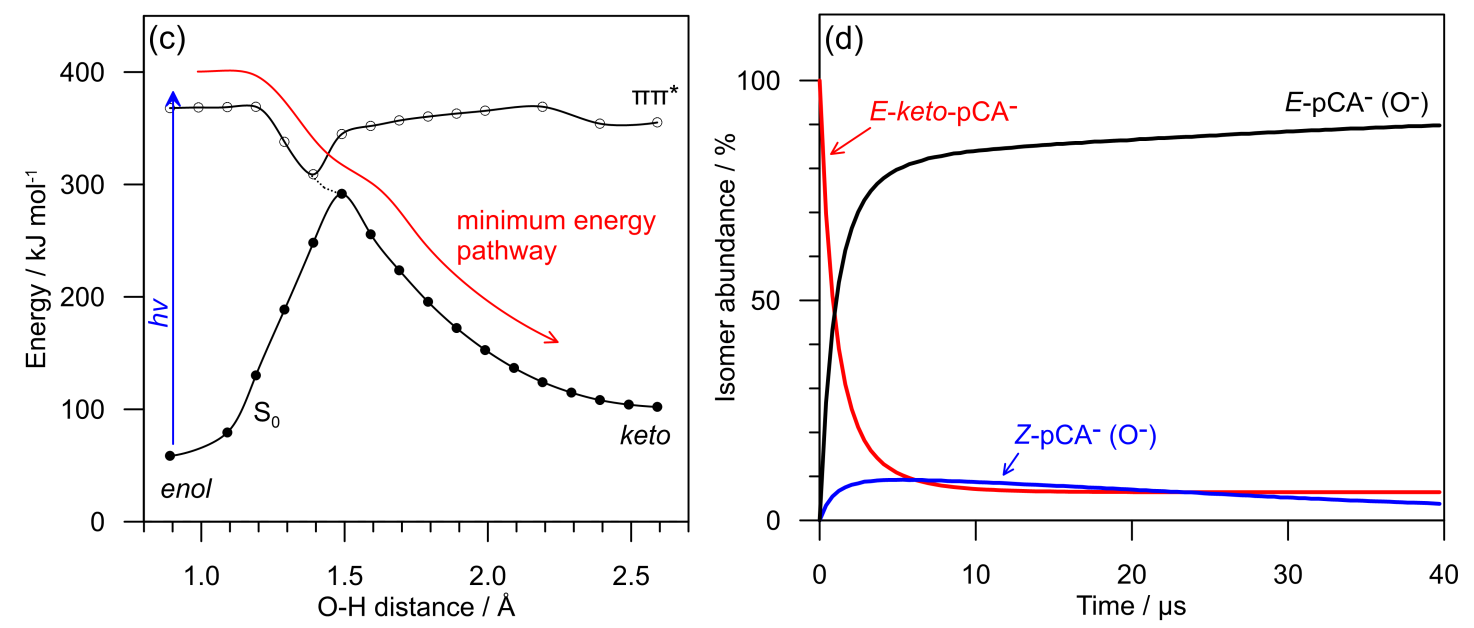

Figure 7: Proposed $E$-pCA $\mathrm{pC}^{-}\left(\mathrm{COO}^{-}\right) \rightarrow E$-pCA ${ }^{-}\left(\mathrm{O}^{-}\right)$proton transfer mechanism: (a) summary of steps, (b) potential energy surface for the proposed mechanism, (c) excited state potential energy surface for the initial photoinduced enol-keto tautomerism calculated at the TD- $\omega$ B97X-D/aug-cc-pVTZ level of theory, and (d) master equation modelling of the isomer populations with time, commencing at $t=0$ with vibrationally energized Z-keto$\mathrm{pCA}^{-}$ions formed by absorption of a $360 \mathrm{~nm}$ photon. Note, energies in (b) and (c) are relative to $E$ - $\mathrm{pCA}^{-}\left(\mathrm{O}^{-}\right)$. The gray pathway in (b) is discussed in the text.

\section{Conclusions}

In this study we have characterized several key photochemical properties of isolated paracinnamate anions through experiments in which the target isomers were selected and probed 
in a tandem ion mobility spectrometer. To avoid ambiguities regarding the deprotonation site we also characterised the deprotonated methyl ester and methyl ether anions (phenolate and carboxylate forms). Depending on the target isomer, action spectra were recorded by monitoring photodetached electrons, photoisomerization or photodepletion. The experimental data were interpreted with the aid of electronic structure calculations for relevant isomers and statistical rate calculations describing isomerization processes occurring on the ground state potential energy surfaces. The main conclusions are as follows.

- Using electrospray ionization it is possible to form deprotonated para-coumaric anions that include the $E$ phenolate deprotomer and $E$ and $Z$ carboxylate deprotomers, with relative abundances influenced by ion source conditions. The phenoxide and carboxylate deprotomers have appreciably different collision cross-sections with $\mathrm{N}_{2}$ and are easily distinguished using ion mobility spectrometry.

- The $E$ phenoxide deprotomer of para-coumaric acid has a similar photodetachment action spectrum to the methyl ester (for which the deprotonation site is unambiguous). In both cases, the maximum photoresponse is at $430 \mathrm{~nm}$.

- Photoexcitation of the $E$ carboxylate deprotomer of para-coumaric acid over the $\pi \pi^{*}$ band (290-385 $\mathrm{nm}$ range) apparently leads to formation of the $E$ phenoxide deprotomer through a process involving enol-keto phototautomerism followed by statistical rearrangements. The maximum photoresponse for the process occurs at $360 \mathrm{~nm}$.

- The $Z$ isomer of the carboxylate deprotomer of para-coumaric acid does not undergo phototautomerism but rather photoisomerizes to the $E$ carboxylate deprotomer.

Overall, the work emphasises the importance of characterizing and controlling isomer populations in gas-phase photochemical experiments, and highlights the utility of approaches in which isobaric ions are selected according to their shape prior to spectroscopic interrogation. 


\section{Acknowledgement}

This research was funded through the Australian Research Council (ARC) Discovery Project scheme (DP150101427 and DP160100474), and Future Fellowship scheme (FT130101304). J.N.B. acknowledges resources from the Australian National Computational Infrastructure (NCI) through Early Career Allocation ya1 and a Microsoft Azure Research Award. M.S.S. thanks the ARC for an Australian Postgraduate Award scholarship. E.C. acknowledges support by the Austrian Science Fund (FWF) through a Schrödinger Fellowship (Nr. J4013N36). Prof. Lars Andersen, Aarhus University, is thanked for providing data from Ref. 36.

\section{Supporting Information Available}

Supporting Information for this article is given via a link at the end of the document. The information includes, structures, energies and collision cross-sections of different $\mathrm{pCA}^{-}$isomers, transition state energies, summary of calculated excitation and detachment energies, master equation parameterization, details of experimental collision cross-section measurements, absorption spectra of pCA, pCEs and pCEt in methanol, ATDs for $\mathrm{pCA}^{-}$in $\mathrm{N}_{2}$ $+\approx 1 \%$ propan-2-ol buffer gas, assignment of the major photoisomer from photoisomerization of $E$-pCA ${ }^{-}\left(\mathrm{COO}^{-}\right)$, relative yields of $E$-keto-pCA ${ }^{-}$and $E$-pCA ${ }^{-}\left(\mathrm{O}^{-}\right)$from $E$-pCA $\left(\mathrm{COO}^{-}\right)$with light fluence, details of the photofragmentation of $E-\mathrm{pCA}\left(\mathrm{O}^{-}\right)$at high light fluence.

\section{References}

(1) Meyer, T. Isolation and Characterization of Soluble Cytochromes, Ferredoxins and Other Chromophoric Proteins From the Halophilic Phototrophic Bacterium Ectothiorhodospira halophila. Biochim. Biophys. Acta-Bioenergetics 1985, 806, 175-183. 
(2) Meyer, T. E.; Yakali, E.; Cusanovich, M. A.; Tollin, G. Properties of a Water-Soluble, Yellow Protein Isolated From a Halophilic Phototrophic Bacterium that has Photochemical Activity Analogous to Sensory Rhodopsin. Biochem. 1987, 26, 418-423.

(3) Kort, R.; Vonk, H.; Xu, X.; Hoff, W. D.; Crielaard, W.; Hellingwerf, K. J. Evidence For Trans-Cis Isomerization of the $p$-Coumaric Acid Chromophore as the Photochemical Basis of the Photocycle of Photoactive Yellow Protein. FEBS Lett. 1996, 382, 73-78.

(4) Sprenger, W. W.; Hoff, W. D.; Armitage, J. P.; Hellingwerf, K. J. The Eubacterium Ectothiorhodospira halophila is Negatively Phototactic, With a Wavelength Dependence that Fits the Absorption Spectrum of the Photoactive Yellow Protein. J. Bacteriol. 1993, 175, 3096-3104.

(5) van Wilderen, L. J. G. W.; van der Horst, M. A.; van Stokkum, I. H. M.; Hellingwerf, K. J.; van Grondelle, R.; Groot, M. L. Ultrafast Infrared Spectroscopy Reveals a Key Step For Successful Entry Into the Photocycle for Photoactive Yellow Protein. Proc. Nat. Acad. Sci. 2006, 103, 15050-15055.

(6) Kuramochi, H.; Takeuchi, S.; Yonezawa, K.; Kamikubo, H.; Kataoka, M.; Tahara, T. Probing the Early Stages of Photoreception in Photoactive Yellow Protein With Ultrafast Time-Domain Raman Spectroscopy. Nat. Chem. 2017, 9, 660-666.

(7) Schotte, F.; Cho, H. S.; Kaila, V. R. I.; Kamikubo, H.; Dashdorj, N.; Henry, E. R.; Graber, T. J.; Henning, R.; Wulff, M.; Hummer, G. et al. Watching a Signaling Protein Function in Real Time via 100-ps Time-Resolved Laue Crystallography. Proc. Nat. Acad. Sci 2012, 109, 19256-19261.

(8) Jung, Y. O.; Lee, J. H.; Kim, J.; Schmidt, M.; Moffat, K.; Šrajer, V.; Ihee, H. VolumeConserving Trans-Cis Isomerization Pathways in Photoactive Yellow Protein Visualized by Picosecond X-Ray Crystallography. Nat. Chem. 2013, 5, 212-220. 
(9) Tenboer, J.; Basu, S.; Zatsepin, N.; Pande, K.; Milathianaki, D.; Frank, M.; Hunter, M.; Boutet, S.; Williams, G. J.; Koglin, J. E. et al. Time-Resolved Serial Crystallography Captures High-Resolution Intermediates of Photoactive Yellow Protein. Science 2014, $346,1242-1246$.

(10) Pande, K.; Hutchison, C. D. M.; Groenhof, G.; Aquila, A.; Robinson, J. S.; Tenboer, J.; Basu, S.; Boutet, S.; DePonte, D. P.; Liang, M. et al. Femtosecond Structural Dynamics Drives the Trans/Cis Isomerization in Photoactive Yellow Protein. Science 2016, 352, 725-729.

(11) Yamaguchi, S.; Kamikubo, H.; Kurihara, K.; Kuroki, R.; Niimura, N.; Shimizu, N.; Yamazaki, Y.; Kataoka, M. Low-Barrier Hydrogen Bond in Photoactive Yellow Protein. Proc. Nat. Acad. Sci. 2009, 106, 440-444.

(12) Joshi, C. P.; Otto, H.; Hoersch, D.; Meyer, T. E.; Cusanovich, M. A.; Heyn, M. P. Strong Hydrogen Bond between Glutamic Acid 46 and Chromophore Leads to the Intermediate Spectral Form and Excited State Proton Transfer in the Y42F Mutant of the Photoreceptor Photoactive Yellow Protein. Biochemistry 2009, 48, 9980-9993.

(13) Carroll, E. C.; Song, S.-H.; Kumauchi, M.; van Stokkum, I. H. M.; Jailaubekov, A.; Hoff, W. D.; Larsen, D. S. Subpicosecond Excited-State Proton Transfer Preceding Isomerization During the Photorecovery of Photoactive Yellow Protein. J. Phys. Chem. Lett. 2010, 1, 2793-2799.

(14) Fraser, C. M.; Chapple, C. The Phenylpropanoid Pathway in Arabidopsis. Arabidopsis Book 2011, 9, e0152.

(15) Baker, L. A.; Horbury, M. D.; Greenough, S. E.; Allais, F.; Walsh, P. S.; Habershon, S.; Stavros, V. G. Ultrafast Photoprotecting Sunscreens in Natural Plants. J. Phys. Chem. Lett. 2016, 7, 56-61. 
(16) Dean, J. C.; Kusaka, R.; Walsh, P. S.; Allais, F.; Zwier, T. S. Plant Sunscreens in the UV-B: Ultraviolet Spectroscopy of Jet-Cooled Sinapoyl Malate, Sinapic Acid, and Sinapate Ester Derivatives. J. Am. Chem. Soc. 2014, 136, 14780-14795.

(17) Baker, L. A.; Staniforth, M.; Flourat, A. L.; Allais, F.; Stavros, V. G. Gas-Solution Phase Transient Absorption Study of the Plant Sunscreen Derivative Methyl Sinapate. ChemPhotoChem 2018, 2, 743-748.

(18) Tan, E. M. M.; Hilbers, M.; Buma, W. J. Excited-State Dynamics of Isolated and Microsolvated Cinnamate-Based UV-B Sunscreens. J. Phys. Chem. Lett. 2014, 5, 24642468.

(19) Changenet-Barret, P.; Espagne, A.; Charier, S.; Baudin, J.-B.; Jullien, L.; Plaza, P.; Hellingwerf, K. J.; Martin, M. M. Early Molecular Events in the Photoactive Yellow Protein: Role of the Chromophore Photophysics. Photochem. Photobiol. Sci. 2004, 3, 823-829.

(20) El-Gezawy, H.; Rettig, W.; Danel, A.; Jonusauskas, G. Probing the Photochemical Mechanism in Photoactive Yellow Protein. J. Phys. Chem. B 2005, 109, 18699-18705.

(21) Espagne, A.; Paik, D. H.; Changenet-Barret, P.; Martin, M. M.; Zewail, A. H. Ultrafast Photoisomerization of Photoactive Yellow Protein Chromophore Analogues in Solution: Influence of the Protonation State. ChemPhysChem 2006, 7, 1717-1726.

(22) Espagne, A.; Changenet-Barret, P.; Plaza, P.; Martin, M. M. Solvent Effect on the Excited-State Dynamics of Analogues of the Photoactive Yellow Protein Chromophore. J. Phys. Chem. A 2006, 110, 3393-3404.

(23) Stahl, A. D.; Hospes, M.; Singhal, K.; van Stokkum, I.; van Grondelle, R.; Groot, M. L.; Hellingwerf, K. J. On the Involvement of Single-Bond Rotation in the Primary Photochemistry of Photoactive Yellow Protein. Biophys. J. 2011, 101, 1184-1192. 
(24) Kuramochi, H.; Takeuchi, S.; Tahara, T. Ultrafast Structural Evolution of Photoactive Yellow Protein Chromophore Revealed by Ultraviolet Resonance Femtosecond Stimulated Raman Spectroscopy. J. Phys. Chem. Lett. 2012, 3, 2025-2029.

(25) Changenet-Barret, P.; Lacombat, F.; Plaza, P. Reaction-Coordinate Tracking in the Excited-State Deactivation of the Photoactive Yellow Protein Chromophore in Solution. J. Photochem. Photobiol. A: Chem. 2012, 234, 171-180.

(26) Gromov, E. V.; Burghardt, I.; Hynes, J. T.; Köppel, H.; Cederbaum, L. S. Electronic Structure of The Photoactive Yellow Protein Chromophore: Ab Initio Study of The Low-Lying Excited Singlet States. J. Photochem. Photobiol. A: Chem. 2007, 190, 241257.

(27) Ko, C.; Virshup, A. M.; Martínez, T. J. Electrostatic Control of Photoisomerization in the Photoactive Yellow Protein Chromophore: Ab initio Multiple Spawning Dynamics. Chem. Phys. Lett. 2008, 460, 272-277.

(28) Virshup, A. M.; Punwong, C.; Pogorelov, T. V.; Lindquist, B. A.; Ko, C.; Martínez, T. J. Photodynamics in Complex Environments: Ab Initio Multiple Spawning Quantum Mechanical/Molecular Mechanical Dynamics. J. Phys. Chem. B 2009, 113, 3280-3291.

(29) Boggio-Pasqua, M.; Groenhof, G. Controlling the Photoreactivity of the Photoactive Yellow Protein Chromophore by Substituting at the p-Coumaric Acid Group. J. Phys. Chem. B 2011, 115, 7021-7028.

(30) Isborn, C. M.; Götz, A. W.; Clark, M. A.; Walker, R. C.; Martínez, T. J. Electronic Absorption Spectra From MM and Ab Initio QM/MM Molecular Dynamics: Environmental Effects on the Absorption Spectrum of Photoactive Yellow Protein. J. Chem. Theo. Comput. 2012, 8, 5092-5106.

(31) García-Prieto, F. F.; Muñoz Losa, A.; Sánchez, M. L.; Martín, M. E.; Aguilar, M. A. Solvent Effects on De-Excitation Channels in the $p$-Coumaric Acid Methyl Ester Anion, 
An Analogue of the Photoactive Yellow Protein (PYP) Chromophore. Phys. Chem. Chem. Phys. 2016, 18, 27476-27485.

(32) García-Prieto, F. F.; Muñoz Losa, A.; Fdez. Galván, I.; Sánchez, M. L.; Aguilar, M. A.; Martín, M. E. QM/MM Study of Substituent and Solvent Effects on the Excited State Dynamics of the Photoactive Yellow Protein Chromophore. J. Chem. Theo. Comput. 2017, 13, 737-748.

(33) Almasian, M.; Grzetic, J.; van Maurik, J.; Steill, J. D.; Berden, G.; Ingemann, S.; Buma, W. J.; Oomens, J. Non-Equilibrium Isomer Distribution of the Gas-Phase Photoactive Yellow Protein Chromophore. J. Phys. Chem. Lett. 2012, 3, 2259-2263.

(34) Xia, H.; Attygalle, A. B. Effect of Electrospray Ionization Source Conditions on the Tautomer Distribution of Deprotonated p-Hydroxybenzoic Acid in the Gas Phase. Anal. Chem. 2016, 88, 6035-6043.

(35) Nielsen, I. B.; Boyé-Péronne, S.; El Ghazaly, M. O.; Kristensen, M. B.; Brøndsted Nielsen, S.; Andersen, L. H. Absorption Spectra of Photoactive Yellow Protein Chromophores in Vacuum. Biophys. J. 2005, 89, 2597-2604.

(36) Rocha-Rinza, T.; Christiansen, O.; Rajput, J.; Gopalan, A.; Rahbek, D. B.; Andersen, L. H.; Bochenkova, A. V.; Granovsky, A. A.; Bravaya, K. B.; Nemukhin, A. V. et al. Gas Phase Absorption Studies of Photoactive Yellow Protein Chromophore Derivatives. J. Phys. Chem. A 2009, 113, 9442-9449.

(37) Rocha-Rinza, T.; Christiansen, O.; Rahbek, D. B.; Klærke, B.; Andersen, L. H.; Lincke, K.; Nielsen, M. B. Spectroscopic Implications of the Electron Donor-Acceptor Effect in the Photoactive Yellow Protein Chromophore. Chem. Eur. J. 2010, 16, 1197711984.

(38) Andersen, L. H.; Bochenkova, A. V.; Houmøller, J.; Kiefer, H. V.; Lattouf, E.; Stock- 
ett, M. H. A PYP Chromophore Acts as a 'Photoacid' in an Isolated Hydrogen Bonded Complex. Phys. Chem. Chem. Phys. 2016, 18, 9909-9913.

(39) Mooney, C. R. S.; Parkes, M. A.; Iskra, A.; Fielding, H. H. Controlling Radical Formation in the Photoactive Yellow Protein Chromophore. Angew. Chem. Int. Ed. 2015, $54,5646-5649$.

(40) Parkes, M. A.; Phillips, C.; Porter, M. J.; Fielding, H. F. Controlling Electron Emission From the Photoactive Yellow Protein Chromophore by Substitution at the Coumaric Acid Group. Phys. Chem. Chem. Phys. 2016, 18, 10329-10336.

(41) Henley, A.; Diveky, M. E.; Patel, A. M.; Parkes, M. A.; Anderson, J. C.; Fielding, H. H. Electronic Structure and Dynamics of Torsion-Locked Photoactive Yellow Protein Chromophores. Phys. Chem. Chem. Phys. 2017, 19, 31572-31580.

(42) Henley, A.; Diveky, M. E.; Patel, A. M.; Parkes, M. A.; Anderson, J. C.; Fielding, H. H. The Role of Photoisomerisation on the Photodetachment of the Photoactive Yellow Protein Chromophore. J. Phys. Chem. A 2018, 122, 8222-8228.

(43) Adamson, B. D.; Coughlan, N. J. A.; Continetti, R. E.; Bieske, E. J. Changing the Shape of Molecular Ions: Photoisomerization Action Spectroscopy in the Gas Phase. Phys. Chem. Chem. Phys. 2013, 15, 9540-9548.

(44) Adamson, B. D.; Coughlan, N. J. A.; Markworth, P. B.; Continetti, R. E.; Bieske, E. J. An Ion Mobility Mass Spectrometer for Investigating Photoisomerization and Photodissociation of Molecular Ions. Rev. Sci. Instr. 2014, 85, 123109.

(45) Bull, J. N.; Carrascosa, E.; Mallo, N.; Scholz, M. S.; da Silva, G.; Beves, J. E.; Bieske, E. J. Photoswitching an Isolated Donor-Acceptor Stenhouse Adduct. J. Phys. Chem. Lett. 2018, 9, 665-671. 
(46) Bull, J. N.; Scholz, M.; Carrascosa, E.; da Silva, G.; Bieske, E. J. Double Molecular Photoswitch Driven by Light and Collisions. Phys. Rev. Lett. 2018, 120, 223002.

(47) Frisch, M. J.; Trucks, G. W.; Schlegel, H. B.; Scuseria, G. E.; Robb, M. A.; Cheeseman, J. R.; Scalmani, G.; Barone, V.; Mennucci, B.; Petersson, G. A. et al. Gaussian 16 Revision A.03. Gaussian Inc. Wallingford CT 2016.

(48) Turney, J. M.; Simmonett, A. C.; Parrish, R. M.; Hohenstein, E. G.; Evangelista, F.; Fermann, J. T.; Mintz, B. J.; Burns, L. A.; Wilke, J. J.; Abrams, M. L. et al. Psi4: An Open-Source Ab Initio Electronic Structure Program. WIREs Comput. Mol. Sci. 2012, 2, 556-565.

(49) Shao, Y.; Gan, Z.; Epifanovsky, E.; Gilbert, A. T.; Wormit, M.; Kussmann, J.; Lange, A. W.; Behn, A.; Deng, J.; Feng, X. et al. Advances in Molecular Quantum Chemistry Contained in the Q-Chem 4 Program Package. Mol. Phys. 2015, 113, 184215.

(50) CFOUR, A Quantum Chemical Program Package Written by J. F. Stanton, J. Gauss, L. Cheng, M. E. Harding, D. A. Matthews, P. G. Szalay With Contributions From A. A. Auer, R. J. Bartlett, U. Benedikt, C. Berger, D. E. Bernholdt, Y. J. Bomble, O. Christiansen, F. Engel, R. Faber, M. Heckert, O. Heun, C. Huber, T.-C. Jagau, D. Jonsson, J. Jusélius, K. Klein, W. J. Lauderdale, F. Lipparini, T. Metzroth, L. A. Mück, D. P. O’Neill, D.R. Price, E. Prochnow, C. Puzzarini, K. Ruud, F. Schiffmann, W. Schwalbach, C. Simmons, S. Stopkowicz, A. Tajti, J. Vázquez, F. Wang, J.D. Watts and the Integral Packages MOLECULE (J. Almlöf and P. R. Taylor), PROPS (P. R. Taylor), ABACUS (T. Helgaker, H. J. Aa. Jensen, P. Jørgensen, and J. Olsen), and ECP Routines by A. V. Mitin and C. van Wüllen. For the Current Version, see http://www.cfour.de. 
(51) Dunning, Jr., T. H. Gaussian Basis Sets for Use in Correlated Molecular Calculations. I. The Atoms Boron Through Neon and Hydrogen. J. Chem. Phys. 1989, 90, 1007.

(52) Chai, J.-D.; Head-Gordon, M. Long-Range Corrected Hybrid Density Functionals with Damped Atom-Atom Dispersion Corrections. Phys. Chem. Chem. Phys. 2008, 10, $6615-6620$.

(53) DePrince, A. E.; Sherrill, C. D. Accurate Noncovalent Interaction Energies Using Truncated Basis Sets Based on Frozen Natural Orbitals. J. Chem. Theory Comput. 2013, 9, 293-299.

(54) Pople, J. A.; Head-Gordon, M.; Raghavachari, K. Quadratic Configuration Interaction - A General Technique for Determining Electron Correlation Energies. J. Chem. Phys. 1987, 87, 5968-5975.

(55) Krylov, A. I. Equation-of-Motion Coupled-Cluster Methods for Open-Shell and Electronically Excited Species: The Hitchhiker's Guide to Fock Space. Ann. Rev. Phys. Chem. 2008, 59, 433-462.

(56) Koch, H.; Jensen, H.; Jørgensen, P.; Helgaker, T. Excitation Energies From The Coupled Cluster Singles and Doubles Linear Response Function (CCSDLR). Applications to Be, $\mathrm{CH}^{+}, \mathrm{CO}$, and $\mathrm{H}_{2}$ O. J. Chem. Phys. 1990, 93, 3345 .

(57) Christiansen, O.; Koch, H.; Jörgensen, P. Response Functions in The CC3 Iterative Triple Excitation Model. J. Chem. Phys. 1995, 103, 7429.

(58) Stanton, J. F.; Gauss, J. Analytic Energy Derivatives for Ionized States Described by The Equation-of-Motion Coupled Cluster Method. J. Chem. Phys. 1994, 101, 8938.

(59) Zuev, D.; Bravaya, K. B.; Crawford, T. D.; Lindh, R.; Krylov, A. I. Electronic Structure of the Two Isomers of the Anionic Form of $p$-Coumaric Acid Chromophore. J. Chem. Phys. 2011, 134, 034310. 
(60) DiStasio, Jr., R. A.; Steele, R. P.; Rhee, Y. M.; Shao, Y.; Head-Gordon, M. An Improved Algorithm for Analytical Gradient Evaluation in Resolution-of-the-Identity SecondOrder Møller-Plesset Perturbation Theory: Application to Alanine Tetrapeptide Conformational Analysis. J. Comput. Chem. 2007, 28, 839-856.

(61) Frisch, M. J.; Pople, J. A.; Binkley, J. S. Self-Consistent Molecular Orbital Methods. 25. Supplementary Functions for Gaussian Basis Sets. J. Chem. Phys. 1984, 80, 3265-3269.

(62) Campuzano, I.; Bush, M. F.; Robinson, C. V.; Beaumont, C.; Richardson, K.; Kim, H.; Kim, H. I. Structural Characterization of Drug-Like Compounds by Ion Mobility Mass Spectrometry: Comparison of Theoretical and Experimentally Derived Nitrogen Collision Cross Sections. Anal. Chem. 2012, 84, 1026-1033.

(63) Mesleh, M. F.; Hunter, J. M.; Shvartsburg, A. A.; Schatz, G. C.; Jarrold, M. F. Structural Information From Ion Mobility Measurements: Effects of the Long-Range Potential. J. Phys. Chem. 1996, 100, 16082-16086.

(64) Besler, B. H.; Merz, Jr., K. M.; Kollman, P. A. Atomic Charges Derived From Semiempirical Methods. J. Comp. Chem. 1990, 11, 431-439.

(65) Barker, J. R. Multiple-Well, Multiple-Path Unimolecular Reaction Systems. I. MultiWell Computer Program Suite. Int. J. Chem. Kinet. 2001, 33, 232-245.

(66) Barker, J. R. Energy Transfer in Master Equation Simulations: A New Approach. Int. J. Chem. Kinet. 2009, 41, 748-763.

(67) Barker, J. R.; Nguyen, T. L.; Stanton, J. F.; Aieta, C.; Ceotto, M.; Gabas, F.; Kumar, T. J. D.; Li, C. G. L.; Lohr, L. L.; Maranzana, A. et al. MultiWell-2017 Software Suite. University of Michigan, Ann Arbor, Michigan, USA, 2017; http://claspresearch.engin.umich.edu/multiwell/. 
(68) Bull, J. N.; Coughlan, N. J. A.; Bieske, E. J. Protomer-Specific Photochemistry Investigated Using Ion Mobility Mass Spectrometry. J. Phys. Chem. A 2017, 121, 6021-6027.

(69) Bull, J. N.; Scholz, M. S.; Coughlan, N. J. A.; Bieske, E. J. Isomerisation of an Intramolecular Hydrogen-Bonded Photoswitch: Protonated Azobis(2-imidazole). Phys. Chem. Chem. Phys. 2017, 19, 12776-12783.

(70) Gidden, J.; Bowers, M. T. Gas-Phase Conformations of Deprotonated Trinucleotides $\left(\mathrm{dGTT}^{-}, \mathrm{dTGT}^{-}\right.$, and $\left.\mathrm{dTTG}^{-}\right)$: The Question of Zwitterion Formation. J. Am. Chem. Mass Spectrom. 2003, 14, 161-170.

(71) Adamson, B. D.; Coughlan, N. J. A.; da Silva, G.; Bieske, E. J. Photoisomerization Action Spectroscopy of the Carbocyanine Dye DTC $(+)$ in the Gas Phase. J. Phys. Chem. A 2013, 117, 13319-13325.

(72) Bull, J. N.; Scholz, M. S.; Carrascosa, E.; Bieske, E. J. From $E$ to $Z$ and Back Again: Reversible Photoisomerisation of an Isolated Charge-Tagged Azobenzene. Phys. Chem. Chem. Phys. 2018, 20, 509-513.

(73) Basarić, N.; Došlić, N.; Ivković, J.; Wang, Y.-H.; Malis, M.; Wan, P. Very Efficient Generation of Quinone Methides Through Excited State Intramolecular Proton Transfer to a Carbon Atom. Chem. Eur. J. 2012, 18, 10617-10523.

(74) Basarić, N.; Došlić, N.; Ivković, J.; Wang, Y.-H.; Veljković, J.; Mlinarić-Majerski, K.; Wan, P. Excited State Intramolecular Proton Transfer (ESIPT) From Phenol to Carbon in Selected Phenylnaphthols and Naphthylphenols. J. Org. Chem. 2013, 78, 1811-1823.

(75) Wang, Y.-H.; Wan, P. Solvent-Dependent Excited State Intramolecular Proton Transfer (ESIPT) Pathways From Phenol to Carbon in 2,5-Dihydroxyphenyl Arenes. Photochem. Photobiol. Sci. 2013, 12, 1571-1588. 
(76) Ma, J.; Zhang, X.; Basaric, N.; Wan, P.; Phillips, D. L. Observation of Excited State Proton Transfer Reactions in 2-Phenylphenol and 2-Phenyl-1-naphthol and Formation of Quinone Methide Species. Phys. Chem. Chem. Phys. 2015, 17, 9205-9211. 


\section{Graphical TOC Entry}

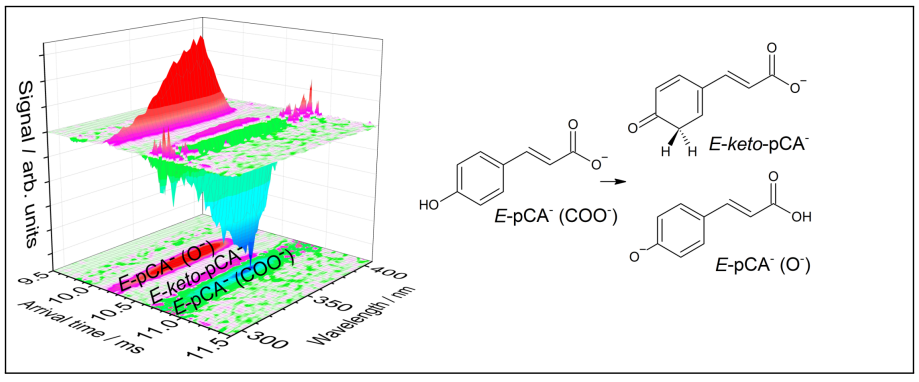

